\title{
Pharmacology of vascular control
}

\author{
R. G. SHANKS \\ M.D., D.Sc. \\ Department of Therapeutics and Pharmacology, The Queen's University of Belfast, \\ Northern Ireland
}

Professor Neil has discussed, in the preceding paper, the physiological control of the circulation. This control depends for its proper functioning on the action of transmitter substances in various parts of the nervous system. These substances are drugs, for example, acetylcholine and noradrenaline, and have well defined pharmacological properties. The transmitter substance in the brain, in the spinal cord and in the autonomic ganglia is acetylcholine. The final pathway of the transmission of nerve impulses in the autonomic system from the autonomic ganglia is the post-ganglionic fibre. The transmitter substance at sympathetic post-ganglionic nerve endings is noradrenaline and at parasympathetic endings, acetylcholine.

As the sympathetic system, and drugs which effect it, are probably of more relevance to this present meeting, only this subject has been included and in particular the effects of drugs on the arterial side of the circulation.

\section{The sympathetic nervous system}

The sympathetic nervous system exerts powerful control on the arterioles in the peripheral circulation. Normally, tonic activity in these nerves maintains peripheral vascular resistance. Section or blockade of these nerves to a particular region, e.g. the arm, produces a marked dilatation of the blood vessels. The effect of the sympathetic system is maintained through the continued release of noradrenaline from the nerve ending. The action of noradrenaline is terminated by a combination of three processesthe effect of mono-amine oxidase in the region of the nerve ending, uptake of noradrenaline in the noradrenaline pool in the nerve ending and carriage to the liver in the blood where it is metabolized by catechol-o-methyl transferase.

\section{Effect of drugs}

Many drugs have been developed which interfere with these actions of noradrenaline. Guanethidine inhibits transmission in the post-ganglionic sympathetic neurone and in addition depletes or reduces the stores of noradrenaline at the nerve endings. Reserpine has only the latter effect. Methyldopa replaces dopa as a precursor of noradrenaline with the result that methyl-noradrenaline is formed instead of noradrenaline. Methyl-noradrenaline is described as a false transmitter, and as it has about one hundredth the action of noradrenaline, the effect on the sympathetic system is greatly reduced.

These drugs reduce the effects of the sympathetic system and interfere with reflexes which involve an increase in sympathetic activity. The compensatory cardiovascular responses to the Valsalva manoeuvre are altered so that the tachycardia and increase in peripheral resistance, which result in the overshoot in arterial pressure when the manoeuvre is stopped, do not occur.

When noradrenaline is released from sympathetic nerve endings it activates a specialized part of the effector cell which has been termed the 'receptor', or adrenergic receptor. These can be stimulated by noradrenaline released from nerve endings or from the adrenal medulla or other drugs administered, e.g. by intravenous injection.

\section{Receptors}

Little is known about these receptors as they have not been isolated biochemically or histologically. They are a convenient basis by which to explain the mode of action of drugs affecting the adrenergic nervous system. These receptors are part of the effector cell as they do not disappear after degeneration of the sympathetic nerve fibres. They can be activated, not only by neuronally released noradrenaline, but by other administered adrenergic agonists. The receptors may be activated by a group of drugs, including tyramine and ephedrine, which do not have a direct effect on the receptor but act through the release of noradrenaline from the neuronal pool which then activates the receptor to initiate a response.

Adrenergic receptors were classified in 1948 by Ahlquist into two separate groups which he designated alpha and beta. Alpha adrenergic receptors are present chiefly in the peripheral vessels in skin and in the kidney. They are activated selectively by phenylephrine and methoxamine. Beta adrenergic receptors are present in the heart where they are 
responsible for inotropic and chronotropic responses, and in the bronchi and blood vessels in skeletal muscle where activation relaxes smooth muscle. Beta adrenergic receptors are selectively stimulated by isoprenaline and orciprenaline. These drugs have no effect on the alpha adrenergic receptors. Adrenaline and noradrenaline activate both alpha and beta receptors.

Thus the effect of any adrenergic drug depends on the type of receptor which it activates and on the distribution of these receptors. Isoprenaline will increase heart rate, dilate the bronchi and increase forearm blood flow as it activates beta adrenergic receptors which are present in these three sites.

\section{Drugs and adrenergic receptors}

This classification of adrenergic receptors has been vindicated by the development of drugs which selectively block either alpha or beta adrenergic receptors. Drugs, such as phenoxybenzamine, the ergot alkaloids, phentolamine and dibenamine, which have been available for many years, block alpha adrenergic receptors but not beta receptors. These drugs will inhibit the vasoconstrictor action of phenylephrine, adrenaline and noradrenaline but not the inotropic, chronotropic or peripheral vasodilator action of isoprenaline or adrenaline.

The first drug, which would selectively block beta adrenergic receptors, was dichloroisoprenaline which was described by Powell and Slater in 1958. Since then many other drugs with this property have been discovered. These include pronethalol, propranolol and oxprenolol. These drugs block the effects of isoprenaline on beta adrenergic receptors. Practolol selectively antagonizes the effects of isoprenaline on beta adrenergic receptors in the heart (beta 1) but not those in the smooth muscle of the bronchi or blood vessels in skeletal muscle (beta 2).

The effects of drugs on the peripheral circulation in man has been studied using venous occlusion plethysmography to measure blood flow to hand or forearm. The former reflects changes in skin blood flow and the latter changes in blood flow to muscle. The drugs can be administered either by injection into the brachial artery or by intravenous injection.
The intra-arterial injection of noradrenaline and phenylephrine decreases blood flow to the hand in normal subjects. A similar response occurs after acute division of the sympathetic fibres to an arm and also after chronic degeneration of the nerves. In contrast, ephedrine and methylamphetamine decrease flow but have no effect after acute or chronic interruption of the sympathetic fibres as these drugs depend for their action on the presence of intact stores of noradrenaline at the sympathetic nerve endings.

The administration of isoprenaline into the brachial artery has little effect on blood flow to the hand but produces a marked increase in forearm blood flow. A similar effect is obtained with orciprenaline. This vasodilator action of both drugs is inhibited by propranolol.

The blood vessels in the skeletal muscles also contain alpha adrenergic receptors as the injection of adrenaline and noradrenaline decreases forearm blood flow. When these receptors are blocked by the prior administration of phentolamine, both drugs increase forearm blood flow through activation of beta adrenergic receptors.

Thus the effect of adrenergic drugs on the peripheral blood vessels depends on a number of interrelated factors including the type of receptor in the vessels in each particular vascular bed, the receptor type activated by the drug and the effects of any other concurrently administered drug. Although these effects have been elucidated for the arterial side of the circulation to the limbs, much less information is available about the venous side and about organs such as the liver and kidney.

\section{References}

AHLQUiST, R.P. (1948) A study of the adrenotropic receptors. American Journal of Physiology, 153, 586.

Brick, I., Hutchison, K.J., McDevitT, D.G., Roddie, I.C. \& SHANKS, R.G. (1968) Comparison of the effects of I.C.I. 50172 and propranolol on the cardiovasular responses to adrenaline, isoprenaline and exercise. British Journal of Pharmacology and Chemotherapy, 34, 127.

Powell, C.E. \& Slater, I.H. (1958) Blocking of inhibitory adrenergic receptors by a dichloro analog of isoproterenol. Journal of Pharmacology and Experimental Therapeutics, $122,480$. 